\title{
Pengaruh Model Resource Based Learning Terhadap Hasil Belajar Ilmu Pengetahuan Sosial (IPS) Siswa Kelas IV SD Sekolah Dasar
}

\author{
Ajat Sudrajat ${ }^{1, *}$, Meiliana Lovienica ${ }^{2}$, Vina Iasha ${ }^{3}$ \\ ${ }^{1}$ Program Studi Pendidikan Guru Sekolah Dasar, Universitas Terbuka, Indonesia \\ ${ }^{2} \mathrm{SD}$ Negeri Abadijaya 1 Depok, Indonesia \\ ${ }^{3}$ SD Negeri Pondok Bambu 06, Jakarta, Indonesia \\ *Email: ajats@ecampus.ut.ac.id
}

\begin{tabular}{|c|c|}
\hline Informasi & strak \\
\hline $\begin{array}{l}\text { Kata kunci: } \\
\text { Model Resource based } \\
\text { Learning, } \\
\text { Hasil Belajar IPS, } \\
\text { Siswa Sekolah Dasar }\end{array}$ & $\begin{array}{l}\text { Tujuan penelitian ini untuk mengetahui ada tidaknya pengaruh model Resource Based } \\
\text { Learning terhadap hasil belajar Ilmu Pengetahuan Sosial (IPS) siswa kelas IV SD di } \\
\text { Kelurahan Abadijaya, Depok dengan pokok bahasan perkembangan teknologi. } \\
\text { Penelitian ini dilaksanakan di SDN Abadijaya } 1 \text { pada semester II tahun ajaran } \\
2019 / 2020 \text {. Sampel diambil dengan menggunakan teknik Cluster Random Sampling dan } \\
\text { desain peneltian Posttest Only Control Goup Design. Pengumpulan data dilakukan dengan } \\
\text { menggunakan tes obyektif berbentuk pilihan ganda dan dianalisis dengan uji } \\
\text { normalitas Lilliefors dan homogenitas dengan uji Fisher baik kelas eksperimen } \\
\text { maupun kelas kontrol. Implikasi dari penelitian ini bahwa model Resource Based } \\
\text { Learning berpengaruh positif terhadap hasil belajar IPS siswa kelas IV SD. Hasil ini } \\
\text { menunjukkan bahwa model Resource Based Learning merupakan salah satu alternatif } \\
\text { yang dapat digunakan dalam proses pembelajaran IPS di kelas. Oleh karena itu, guru } \\
\text { perlu menerapkan model Resource Based Learning sebagai variasi model pembelajaran } \\
\text { yang digunakan untuk mengatasi hasil belajar siswa kelas IV SD. }\end{array}$ \\
\hline $10-02-2021$ & Abstact \\
\hline $\begin{array}{l}\text { Dipubikasikan: } \\
26-02-2021\end{array}$ & $\begin{array}{l}\text { The purpose of this study was to determine whether the Resource Based Learning } \\
\text { model had an effect on learning outcomes of Social Sciences (IPS) for fourth grade } \\
\text { elementary school students in Kelurahan Abadijaya, Depok with the subject of } \\
\text { technological development. This research was conducted at SDN Abadijaya } 1 \text { in the } \\
\text { second semester of the } 2019 / 2020 \text { school year. Samples were taken using the Cluster } \\
\text { Random Sampling technique and the Posttest Only Control Goup Design research } \\
\text { design. The data was collected using an objective test in the form of multiple choices } \\
\text { and analyzed using the Lilliefors normality test and homogeneity using Fisher's test, } \\
\text { both in the experimental class and the control class. The implication of this research } \\
\text { is that the Resource Based Learning model has a positive effect on social studies } \\
\text { learning outcomes for fourth grade elementary school students. These results } \\
\text { indicate that the Resource Based Learning model is an alternative that can be used in } \\
\text { the social studies learning process in the classroom. Therefore, teachers need to apply } \\
\text { the Resource Based Learning model as a variation of the learning model used to } \\
\text { address the learning outcomes of fourth grade elementary school students. }\end{array}$ \\
\hline
\end{tabular}




\section{PENDAHULUAN}

Pendidikan adalah usaha sadar dan terencana untuk mewujudkan suasana belajar dan proses pembelajaran agar siswa dapat mengembangkan potensi yang ada dalam dirinya. Pembelajaran yang berlangsung diharapkan dapat berdampak positif bagi siswa karena dapat memberikan siswa sebuah pengalaman belajar (Rachmadtullah et al., 2020). Pengalaman tersebut akan semakin bermakna jika dalam pembelajaran siswa dapat menggali informasi sendiri dan terlibat langsung di dalamnya, sehingga proses pembelajaran yang diperoleh merupakan hasil pemahaman siswa sendiri (Amirudin \& Widiati, 2017). Pembelajaran seperti itu dapat diaplikasikan untuk setiap mata pelajaran, begitu pula pada mata pelajaran Ilmu Pengetahuan Sosial (IPS).

Roger dalam Dimyati mengemukakan bahwa praktik pendidikan di sekolah menitikberatkan pada segi pengajaran, bukan pada siswa yang belajar (Dimyati dan Mudjiono, 2009). Praktik tersebut ditandai oleh peran guru yang dominan dan siswa hanya menghafal saja. Sejalan dengan pendapat tersebut, saat ini IPS masih dianggap sebagai suatu mata pelajaran yang sulit dipelajari dan membosankan karena selama ini dalam pembelajarannya lebih banyak didominasi oleh guru dan hanya mengandalkan buku pegangan siswa sebagai sumber belajar (Prastyo, 2018; Zaman, 2018). Proses belajar hanya menekankan pada upaya menjejali siswa dengan konsep yang bersifat hafalan (Legi, 2020). Siswa hanya duduk, mendengarkan, diminta membaca buku dan menjawab pertanyaan semampu mereka tanpa memahami benar apa yang sedang mereka pelajari, yang pada akhirnya membuat peserta didik jenuh dalam belajar sehingga berdampak pada rendahnya hasil belajar siswa dan tidak tercapainya Kriteria Ketuntasan Minimal (KKM) pada mata pelajaran IPS. Guru serta segala aspek pembelajaran termasuk sumber belajar merupakan hal yang penting untuk dipersiapkan secara matang. Hal ini dikarenakan memiliki hubungan erat dengan proses pembelajaran yang akan berlangsung.

Siswa perlu diberi kesempatan untuk ikut berperan dalam pembelajaran agar dapat meningkatkan gairah serta hasil belajar, misalnya mencari berbagai informasi yang berhubungan dengan materi yang diajarkan dan menggalinya lebih dalam melalui berbagai sumber belajar (Sari et al., 2020; Yetti et al., 2021). Dengan begitu siswa dapat belajar secara bermakna. Untuk mewujudkannya, guru dapat mengemas sebuah pembelajaran dengan menerapkan model pembelajaran yang tepat sehingga siswa dapat memperoleh hasil belajar yang baik. Salah satu model yang dapat diterapkan adalah model Resource Based Learning. Model Resource Based Learning itu sendiri adalah segala bentuk belajar yang langsung menghadapkan siswa dengan suatu atau sejumlah sumber belajar, siswa dapat belajar dalam kelas, laboratorium, perpustakaan, dan ruang sumber belajar yang khusus atau bahkan di luar sekolah bila siswa mempelajari tentang lingkungan (Wijaya, 2019).

Berdasarkan latar belakang masalah di atas, maka dapat diidentifikasi masalah-masalah diantaranya peran guru yang lebih dominan dalam proses belajar mengajar di kelas, pembelajaran masih lebih sering menggunakan model pembelajaran konvensional, kurangnya pemanfaatan sumber belajar yang digunakan dalam pembelajaran, dan pengaruh model Resource Based Learning terhadap hasil belajar Ilmu Pengetahuan 
Sosial (IPS) siswa. Oleh sebab itu, peneliti bermaksud untuk melakukan penelitian eksperimen untuk meneliti pengaruh model Resource Based Learning terhadap hasil belajar Ilmu Pengetahuan Sosial (IPS) siswa kelas IV.

\section{METODE}

Tujuan penelitian ini adalah untuk mengetahui apakah penerapan model Resource Based Learning berpengaruh terhadap hasil belajar Ilmu Pengetahuan Sosial (IPS) siswa kelas IV SD di Kelurahan Abadijaya Depok. Penelitian ini dilakukan pada siswa kelas IV di SDN Abadijaya 1 yang berlangsung selama 3 bulan pada semester kedua tahun pelajaran 2019/2020, dilakukan sejak bulan Maret sampai Mei 2019.

Dalam penelitian ini metode penelitian yang digunakan adalah metode eksperimen. Peneliti menggunakan kelas eksperimen dan kelas kontrol, untuk mengetahui pengaruh perlakuan dengan membandingkan kelompok yang diberi perlakuan model Resource Based Leaming dengan kelompok yang diberi perlakuan model pembelajaran konvensional. Desain penelitian yang digunakan adalah posttest only control group design. Penelitian ini menggunakan teknik cluster random sampling. Teknik ini merupakan cara pengambilan sampel dengan cara memilih salah satu atau beberapa kelompok secara acak dengan melakukan pengundian. Pada penelitian ini dilakukan pengujian persyaratan instrumen untuk mengetahui validitas dan reliabilitas instrumen. Uji validitas yang digunakan dalam penelitian ini adalah dengan menganalisis butir instrumen. Rumus yang digunakan yaitu korelasi Point Biserial. Uji validitas dari 40 butir instrumen hasil belajar IPS yang dilakukan terhadap 30 responden menunjukkan sebanyak 34 butir atau sebesar $85 \%$ dinyatakan valid Adapun butir soal yang drop berjumlah 6 butir atau sebesar 15\%.

Untuk menghitung reliabilitas digunakan rumus Kuder Richardson 20. Berdasarkan perhitungan didapatkan $r=0,93$. Berdasarkan kriteria klasifikasi dapat disimpulkan bahwa instrumen hasil belajar yang terdiri dari 34 butir soal secara keseluruhan memiliki tingkat kepercayaan butir soal sangat tinggi. Selanjutnya dilakukan perhitungan terhadapa tingkat kesukaran dan daya beda butir soal. Dari perhitungan yang telah dilakukan, tingkat kesukaran dapat dinyatakan sebagai berikut: butir soal yang mudah berjumlah 17 soal, sedang15 soal, dan sukar 8 soal. Dengan proporsi soal yang mudah $42.50 \%$, sedang $37.50 \%$, dan sukar 20\%. Sedangkan daya beda pada 34 butir soal yang telah dibuat sabagai berikut: butir soal dengan daya beda jelek berjumlah 12 soal, cukup 16 soal, baik 10 soal dan baik sekali 2 soal. Dengan proporsi soal dengan daya beda jelek $30 \%$, cukup $40 \%$, baik $25 \%$ dan baik sekali $5 \%$.

Pada penelitian ini tes hasil belajar difokuskan pada ranah kognitif. Soal yang dibuat mengacu pada kisi-kisi berdasarkan Kurikulum Tingkat Satuan Pendidikan (KTSP) 2006. Untuk mengetahui bahwa kelompok eksperimen dan kelompok kontrol dalam keadaan yang homogen dan berdistribusi normal, maka dilakukan uji normalitas dengan menggunakan uji Lilliefors dan uji homogenitas dengan menggunakan uji Fisher. Data yang terkumpul kemudian dianalisis dengan menggunakan uji-t. Hipotesis statistik dari penelitian ini adalah sebagai berikut: 
$\mathrm{H}_{0} \quad: \mu_{1} \leq \mu_{2}$

Siswa yang diajarkan dengan menggunakan model Resource Based Learning memiliki hasil belajar yang lebih rendah atau sama dengan siswa yang dijarkan dengan menggunakan model pembelajaran konvensional

$\mathrm{H}_{1} \quad: \mu_{1}>\mu_{2}$

Siswa yang diajarkan dengan model Resource Based Learning memiliki hasil belajar yang lebih tinggi daripada siswa yang diajarkan dengan model pembelajaran konvensional.

\section{HASIL DAN PEMBAHASAN}

Berdasarkan hasil perhitungan uji normalitas kelas eksperimen diperoleh $\mathrm{L}_{\text {hitung }}$ sebesar 0,0815 dan $\mathrm{L}_{\text {tabel }}$ dengan $\mathrm{n}=30$ dan $\alpha=0,05$ sebesar 0,161 sehingga $\mathrm{L}_{\text {hitung }}<\mathrm{L}_{\text {tabel }}$ maka $\mathrm{H}_{0}$ diterima. Oleh karena itu dapat disimpulkan bahwa data tersebut berdistribusi normal. Kemudian hasil perhitungan uji normalitas kelas kontrol diperoleh $\mathrm{L}_{\text {hitung }}$ sebesar 0,1134 dan $\mathrm{L}_{\text {tabel }}$ sebesar 0,161 sehingga $\mathrm{L}_{\text {hitung }}<\mathrm{L}_{\text {tabel }}$ maka $\mathrm{H}_{0}$ diterima sehingga disimpulkan berdistribusi normal.

Setelah diketahui bahwa data penelitian ini berdistribusi normal maka selanjutnya diperiksa juga homogenitasnya menggunakan uji $\mathrm{F}$ dengan kriteria pengujian $\mathrm{F}_{\text {hitung }}<\mathrm{F}_{\text {tabel. }}$ Dalam pengujian diperoleh harga $F_{\text {hitung }}=1,19$ dan $F_{\text {tabel }}=1,85$. Oleh karena itu $F_{\text {hitung }}<F_{\text {tabel }}$ maka syarat homogenitasnya terpenuhi. Maka dengan taraf signifikansi $\alpha=0,05 \mathrm{H}_{0}$ diterima. Berdasarkan hasil pengujian tersebut diketahui bahwa kedua kelompok berdistribusi normal dan memiliki varian yang homogen.

Selanjutnya hipotesis yang didapat berdasarkan perhitungan uji-t diperoleh harga thitung sebesar 5,75 dan $t_{\text {tabel }}$ sebesar 1,70 pada taraf signifikansi $\alpha=0,05$. Dengan demikian harga thitung $>$ tabel hipotesis nol $\left(\mathrm{H}_{0}\right)$ ditolak hipotesis kerja $\left(\mathrm{H}_{1}\right)$ diterima. Berdasarkan deskripsi data yang telah dianalisis, tampak terdapat pengaruh yang positif dan signifikan dari model Resource Based Learning terhadap hasil belajar Ilmu Pengetahuan Sosial (IPS).

Hasil belajar siswa salah satunya dapat ditentukan oleh bagaimana guru merancang sebuah pembelajaran yang dapat memunculkan potensi yang ada dalam diri siswa. Pembelajaran yang berlangsung di sekolah diharapkan dapat memfasilitasi siswa untuk belajar secara bermakna melalui pengalaman belajar yang siswa rasakan dalam kelas, pengalaman tersebut dapat berupa interaksi dengan guru, sesama siswa maupun berbagai sumber belajar yang disediakan dalam rangka memudahkan siswa dalam belajar. Siswa diharapkan dapat membangun pengetahuannya sendiri melalui proses belajar sehingga dapat mempengaruhi pemahaman siswa terhadap materi pelajaran juga hasil belajar yang akan siswa dapatkan. Hal yang dapat dilakukan adalah dengan memanfaatkan berbagai sumber belajar yang dapat mendukung terjadinya belajar. Dari berbagai model pembelajaran yang ada, salah satu model pembelajaran yang dapat mempengaruhi hasil belajar siswa adalah dengan menerapkan model Resource Based Learning dalam pembelajaran di kelas. Dalam 
model ini, peran guru berkurang. Guru berperan sebagai fasilitator sehingga siswa memiliki keterlibatan dalam proses pembelajaran.

Melalui model pembelajaran ini siswa bersentuhan langsung dengan suatu atau sejumlah sumber belajar baik secara individual maupun kelompok. Model pembelajaran ini melibatkan siswa dalam mencari berbagai informasi yang dibutuhkan dalam belajar, sehingga memberikan kemudahan kepada siswa dalam memaknai dan memahami materi yang diberikan kepadanya. Setiap siswa dapat berinteraksi dengan berbagai sumber belajar secara bermakna dan proses pembelajaran cenderung lebih fleksibel. Siswa menemukan sendiri informasi yang dibutuhkan sehingga terjadi pembelajaran bermakna. Dengan proses belajar seperti itu, siswa akan memahami dengan baik apa yang mereka pelajari sehingga akan berdampak pada hasil belajar yang akan diperoleh siswa.

Dengan demikian dapat dibuktikan bahwa model Resource Based Learning yang telah diterapkan pada kelas eksperimen mempengaruhi hasil belajar siswa khususnya dalam mata pelajaran IPS. Besarnya pengaruh perlakuan model pembelajaran yang diberikan dapat dilihat dari perbedaan hasil belajar yang diperoleh siswa. Nilai rata-rata yang diperoleh kedua kelompok siswa, yaitu pada kelas eksperimen adalah 84,40 sedangkan pada kelas kontrol adalah 72,60. Dari hasil pengujian yang telah dilakukan, dapat dikatakan bahwa terdapat pengaruh positif dan signifikan dari penggunaan model Resource Based Learning terhadap hasil belajar Ilmu Pengetahuan Sosial (IPS) siswa kelas IV SD di Kelurahan Abadijaya Depok.

\section{KESIMPULAN}

Penelitian ini meneliti tentang pengaruh model Resource Based Learning terhadap hasil belajar Ilmu Pengetahuan Siswa (IPS) siswa kelas IV SD di Kelurahan Abadijaya Depok. Penelitian ini dibagi menjadi dua kelompok, yaitu kelompok eksperimen dan kelompok kontrol. Kelompok eksperimen merupakan kelompok yang diberikan perlakuan dengan menggunakan model Resource Based Learning sedangkan kelompok kontrol merupakan kelompok yang diberikan perlakuan dengan menggunakan model pembelajaran konvensional. Berdasarkan penelitian yang telah dilakukan, diperoleh hasil pengujian hipotesis dengan hipotesis nol $\left(\mathrm{H}_{0}\right)$ ditolak dan hipotesis kerja $\left(\mathrm{H}_{1}\right)$ diterima. Dengan ditolaknya hipotesis nol $\left(\mathrm{H}_{0}\right)$ dan diterimanya hipotesis kerja $\left(\mathrm{H}_{1}\right)$ memberikan arti bahwa siswa yang diajarkan dengan model Resource Based Learning memiliki hasil belajar yang lebih tinggi dari pada siswa yang diajarkan dengan model pembelajaran konvensional. Jadi kesimpulannya adalah terdapat pengaruh positif dan signifikan terhadap hasil belajar IPS siswa yang belajar dengan menggunakan model Resource Based Learning. Hasil belajar IPS siswa yang menggunakan model Resource Based Learning lebih tinggi dari siswa yang belajar dengan menggunakan model pembelajaran konvensional. Ini ditunjukkan dengan nilai rata-rata kelas eksperimen lebih besar yaitu 84,40 dari pada kelas kontrol yaitu 72,60. Dengan demikian dapat dikatakan bahwa model Resource Based Learning berpengaruh terhadap hasil belajar Ilmu Pengetahuan Sosial (IPS) siswa kelas IV SD di Kelurahan Abadijaya Depok. 


\section{DAFTAR PUSTAKA}

Amirudin, A., \& Widiati, U. (2017). Pentingnya Pengembangan Bahan Ajar Tematik untuk Mencapai Pembelajaran Bermakna bagi Siswa Sekolah Dasar. Prosiding Seminar Nasional Mahasiswa Kerjasama Direktorat Jenderal Guru Dan Tenaga Kependidikan Kemendikbud 2016.

Campbell, Lisa, et al. 2002. Resource Based Learning. (http://www.coe.uga.edu/epltt/images/RBL.HTM) Diunduh tanggal 18 Januari 2014, pukul 07.00.

Depdiknas. 2006. Kurikulum Tingkat Satuan Pendidikan SD/MI. Jakarta: Depdiknas.

Dimyati dan Mudjiono. 2009. Belajar dan Pembelajaran. Jakarta: Rineka Cipta.

Doiron, Ray and Judy Davies. 1998. Partners in Learning: Students, Teachers, and The School Library. United State of America: Teacher Ideas Press.

Fajar, Arnie. 2009. Portofolio dalam Pelajaran IPS. Bandung: Rosdakarya.

Legi, A. S. J. (2020). PEMANFAATAN LINGKUNGAN SEBAGAI MEDIA UNTUK MENINGKATKAN HASIL BELAJAR IPS SISWA KELAS IV SEKOLAH DASAR. Jurnal Forum Pendidikan, 15(2).

Prastyo, D. (2018). PENGARUH MODEL PELAJARAN TGT DAN TAI TERHADAP HASIL BELAJAR MAHASISWA PGSD UNIPA SURABAYA PADA POKOK BAHASAN KONSEP PENDIDIKAN IPS. Buana Pendidikan: Jurnal Fakultas Keguruan Dan Ilmu Pendidikan, 14(26 SE-), 96104. https://doi.org/10.36456/bp.vol14.no26.a1674

Purwanto. 2009. Evaluasi Hasil Belajar. Yogyakarta: Pustaka Belajar.

Rachmadtullah, R., Yustitia, V., Setiawan, B., Mahya Fanny, A., Pramulia, P., Susiloningsih, W., Tur Rosidah, C., Prastyo, D., \& Ardhian, T. (2020). The Challenge Of Elementary School Teachers To Encounter Superior Generation In The 4.0 Industrial Revolution: Study Literature. International Journal of Scientific \& Technology Research, 9(4), 1879-1882. www.ijstr.org

Rusman. 2012. Model-Model Pembelajaran: Mengembangkan Profesionalisme Guru. Jakarta: Rajawali Press.

Sagala, Syaiful. 2008. Konsep dan Makna Pembelajaran. Bandung: Alfabeta.

Sari, Y., Luvita, R. D., Cahyaningtyas, A. P., Iasha, V., \& Setiawan, B. (2020). Pengaruh Metode Pembelajaran Struktural Analitik Sitentik terhadap Kemampuan Menulis Permulaan di Sekolah Dasar. Jurnal Basicedu, 4(4), 1125-1133.

Siregar, Eveline dan Hartini, Nara. 2010. Teori Belajar dan Pembelajaran. Bogor: Penerbit Ghalia Indonesia.

Wijaya, H. (2019). Resource-based learning: a paradigm shift in materials design. 6th International Conference on Educational Research and Innovation (ICERI 2018), 391-397.

Yetti, E., Yufiarti, Pramitasari, M., Suharti, Iasha, V., \& Setiawan, B. (2021). The Influence of Dance Instructional Strategy and Teacher's Pedagogy Competence on Classroom Climate. Elementary Education Online, 20(1), 642-650. https://doi.org/10.17051/ilkonline.2021.01.54

Zaman, A. Q. (2018). Pengaruh Penggunaan Media Pembelajaran Kreatif Terhadap Hasil Belajar IPS Siswa Sekolah Dasar Negeri Di Surabaya Selatan: Media pembelajaran kreatif, hasil belajar, IPS. Buana Pendidikan: Jurnal Fakultas Keguruan Dan Ilmu Pendidikan, 11(20 SE-). https://doi.org/10.36456/bp.vol11.no20.a1356 